however, persistence of interseptovalvular space with the embryonic left venous valve remnant as the incomplete partition may explain the morphogenesis of the midline chamber. Because of marked asymmetry in the timing and sequence of events for pulmonary venous development, a process of differential pulmonary venous segregation, which supports the primary theory, ${ }^{4}$ may explain right pulmonary vein malincorporation into the midline chamber.

Although appreciation of the developmental basis would not have altered the surgical approach, recognition of precise anatomic disposition of this unusual anomaly is essential for effective planning of the appropriate corrective surgical strategy. Awareness of the exact nature of the pulmonary venous drainage is pivotal to the prevention of pulmonary venous obstruction and its ensuing adverse hemodynamic effects.

\section{References}

1. Uemura H, Ho SY, Devine WA, Kilpatrick LL, Anderson RH. Atrial appendages and venoatrial connections in hearts from patients with visceral heterotaxy. Ann Thorac Surg. 1995;60:561-9.

2. Michaud P, Dallaz C, Agé C. A propos d'un nouveau cas de coeur triatrial de l'adulte opéré avec succés. Arch Mal Coeur. 1970;63:291-300.

3. Thilenius OG, Bharati S, Lev M. Subdivided left atrium: an expanded concept of cor triatriatum sinistrum. Am J Cardiol. 1976;37:743-52.

4. Webb S, Kanani M, Anderson RH, Richardson MK, Brown NA. Development of the human pulmonary vein and its incorporation into the morphologically left atrium. Cardiol Young. 2001;11:632-42.

5. Blom NA, Gittenberger-de Groot A, Jongeneel TH, DeRuiter MC, Poelmann RE, Ottenkamp J. Normal development of the pulmonary veins in human embryos and formulation of a morphogenetic concept for sinus venosus defects. Am J Cardiol. 2001;87:305-9.

\title{
Completion lobectomy after bilateral lung volume reduction for emphysema: Salvage option or fancy?
}

Eugenio Pompeo, MD, Davide Mineo, MD, Patrizio Bollero, MD, Paola Rogliani, MD, Vincenzo Ambrogi, MD, and Tommaso Claudio Mineo, MD, Rome, Italy

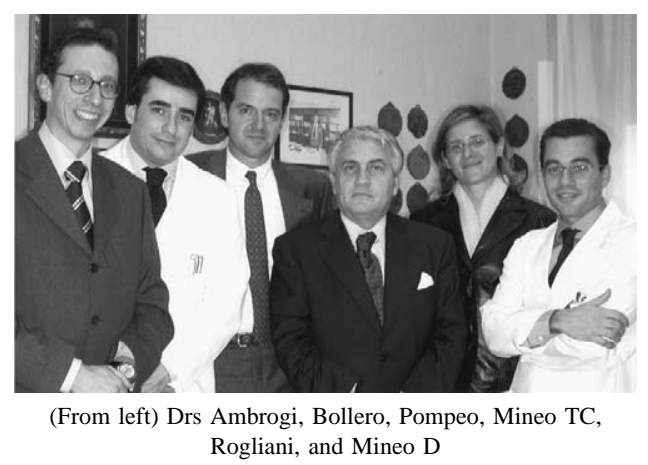

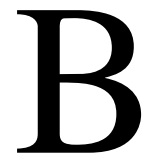

ilateral lung volume reduction (LVR) can significantly improve the functional capacity of selected patients with severe emphysema and an upper-lobe predominance of disease. ${ }^{1,2}$ However, because of its palliative nature, postoperative improvements usually peak within the first 6 months and slowly decline subsequently, eventually returning back to the baseline status in most patients. Little is known, however, as to whether redo $\mathrm{LVR}^{3}$ can be reasonably proposed in selected patients after bilateral LVR.

\footnotetext{
From the Thoracic Surgery and the Multidisciplinary Pulmonary Program, Policlinico University Tor Vergata, Rome, Italy.

This research was supported by Ministero dell'Università e della Ricerca Scientificá e Tecnologica (MURST) Cofinanziamento (COFIN) grants 9906274194-06 and 2001061191-001, Consiglio Nazionale della Ricerca (CNR) CU0100935 2002, and Centro di Eccellenza 2001.

Received for publication Aug 16, 2003; revisions requested Oct 2, 2003; revisions received Nov 3, 2003; accepted for publication Dec 3, 2003.

Address for reprints: Tommaso C. Mineo, MD, Cattedra di Chirurgia Toracica, Università Tor Vergata, Policlinico Tor Vergata, V.le Oxford 81, 00133 Rome, Italy (E-mail: mineo@med.uniroma2.it).

J Thorac Cardiovasc Surg 2004;127:1212-4

$0022-5223 / \$ 30.00$

Copyright $\odot 2004$ by The American Association for Thoracic Surgery

doi:10.1016/j.jtcvs.2003.11.054
}

Herein we describe 4 patients with upper-lobe prevailing emphysema who underwent completion lobectomy (CL) as a redo LVR after a previous bilateral operation. The patients, all men, were operated on between September 2001 and October 2002. All patients gave their written, informed consent. The mean interval between bilateral LVR and CL was 59 months. After the bilateral operation, marked improvements occurred in pulmonary function measures: $+360 \mathrm{~mL}$ in forced expiratory volume in 1 second $\left(\mathrm{FEV}_{1}\right),-1170 \mathrm{~mL}$ in residual volume, $+125 \mathrm{~m}$ in the 6-minute walking test, and $+5.25 \mathrm{~mm} \mathrm{Hg}$ in arterial oxygen tension. Afterward, the $\mathrm{FEV}_{1}$ annual decline averaged $0.23 \pm 0.09 \mathrm{~L}$ at 24 months and $\pm 0.08 \mathrm{~L}$ at 36 months.

$\mathrm{CL}$ was performed when $\mathrm{FEV}_{1}$ returned to baseline values and high-resolution computed tomography showed severe emphysematous lung destruction that was prevailing in 1 upper lobe (Figure 1,1 and 2). Before CL, all patients were receiving maximized medical therapy and underwent a 4-week respiratory rehabilitation program.

CL (3 right upper lobectomies and 1 left upper lobectomy) was performed by video-assisted minithoracotomy ( 2 patients) or lateral thoracotomy ( 2 patients). In 2 instances, isolation of the hilar structures was accomplished in a standard manner. In another 2 patients, the fissure was not dissected free, and the upper lobe tissue was excised through nonbuttressed staple resection (Figure 2). All patients were extubated in the operating room, but 1 required early reintubation and eventually died of respiratory failure. In the remaining 3 patients, there were no major complica- 


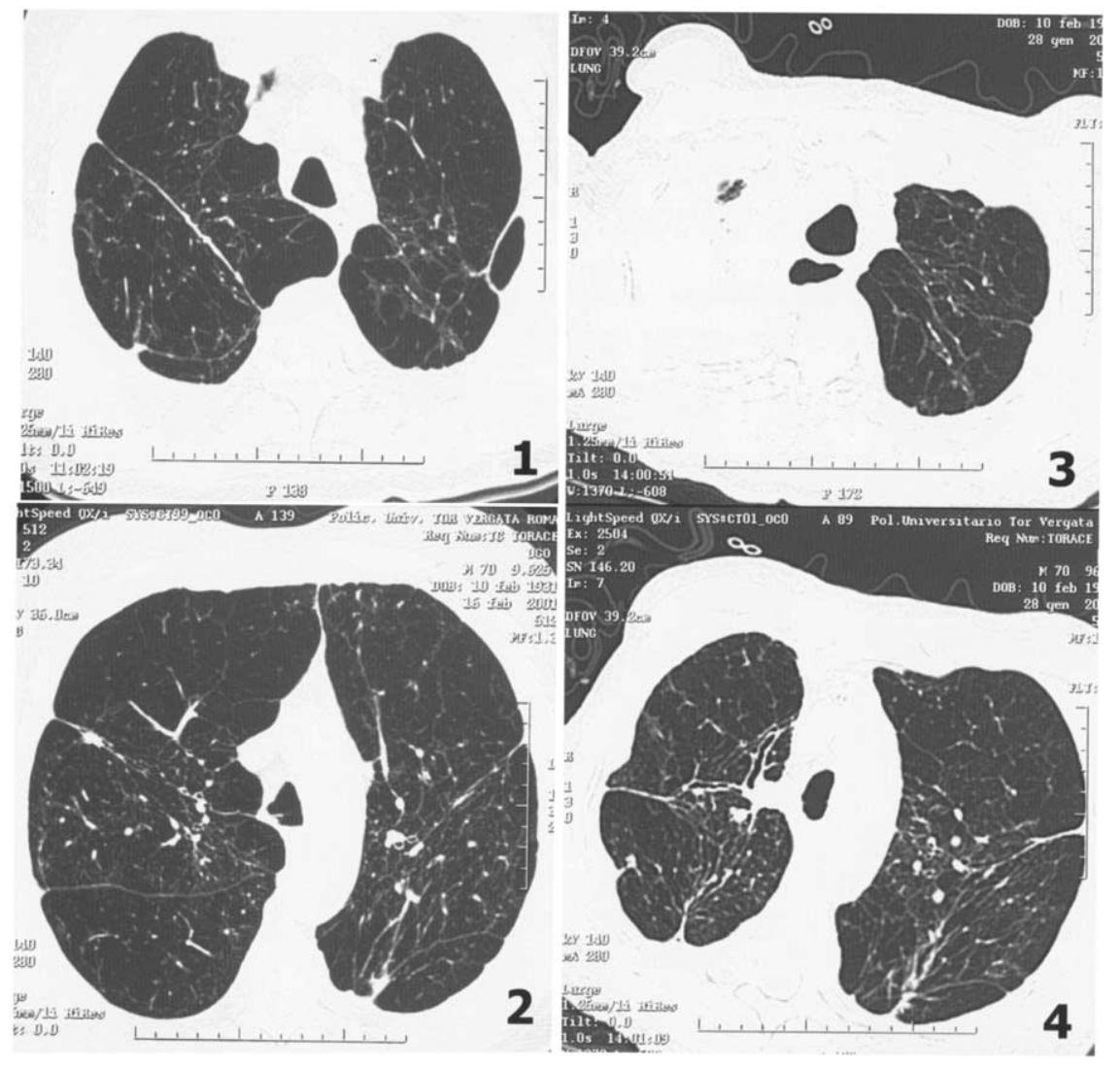

Figure 1. High-resolution computed tomography of a patient who underwent CL after previous bilateral LVR. Before surgery (1 and 2), a completely destroyed and hyperinflated right upper lobe was shown; after surgery (3 and 4), a meaningful reduction in the overall lung volume occurred in both lungs after right upper $\mathrm{CL}$.

TABLE 1. Demographics before and 6 mo after completion lobectomy measures

\begin{tabular}{|c|c|c|c|c|}
\hline Variable & Patient 1 & Patient 2 & Patient 3 & Patient 4 \\
\hline Age (y) & 63 & 66 & 65 & 71 \\
\hline $\begin{array}{l}\text { Interval between bilateral } \\
\text { LVR and } C L(\mathrm{mo})\end{array}$ & 49 & 61 & 64 & 62 \\
\hline Surgical procedure & Right upper CL & Left upper CL & Right upper CL & Right upper CL \\
\hline Morbidity & - & $\begin{array}{l}\text { Prolonged air leak, } \\
\text { respiratory failure }\end{array}$ & Prolonged air leak & - \\
\hline \multicolumn{5}{|l|}{$\mathrm{FEV}_{1}(\mathrm{~L})$} \\
\hline Before CL & 0.72 & 0.52 & 0.71 & 0.60 \\
\hline After CL & 0.80 & - & 0.93 & 0.84 \\
\hline \multicolumn{5}{|l|}{ FVC (L) } \\
\hline Before CL & 1.91 & 1.75 & 1.81 & 1.63 \\
\hline After CL & 2.12 & - & 1.94 & 1.92 \\
\hline \multicolumn{5}{|l|}{$\mathrm{RV}(\mathrm{L})$} \\
\hline Before CL & 4.9 & 5.7 & 5.8 & 5.3 \\
\hline After CL & 4.2 & - & 5.2 & 4.6 \\
\hline \multicolumn{5}{|l|}{ SMWT $(\mathrm{m})$} \\
\hline Before CL & 230 & 180 & 340 & 300 \\
\hline After CL & 290 & - & 420 & 370 \\
\hline \multicolumn{5}{|l|}{$\mathrm{PaO}_{2}(\mathrm{~mm} \mathrm{Hg})$} \\
\hline Before CL & 67 & 57 & 63 & 60 \\
\hline After CL & 69 & - & 67 & 63 \\
\hline \multicolumn{5}{|l|}{ DLCO $(\%)$} \\
\hline Before CL & 38 & 18 & 40 & 36 \\
\hline After CL & 41 & - & 38 & 36 \\
\hline \multicolumn{5}{|l|}{ Systolic PAP (mm Hg) } \\
\hline Before CL & 31 & 42 & 22 & 28 \\
\hline After CL & 30 & - & 27 & 29 \\
\hline Follow-up (mo) & 19 & - & 9 & 23 \\
\hline Status & Alive & Dead & Alive & Alive \\
\hline
\end{tabular}

$C L$, Completion lobectomy; $F E V$, forced expiratory volume in $1 \mathrm{~s}$; $F V C$, forced vital capacity; $R V$, residual volume; $S M W T$, 6-min walking test; $P a 0_{2}$, arterial oxygen tension; $D L C O$, diffusion capacity for carbon monoxide; $P A P$, pulmonary artery pressure; $L V R$, lung volume reduction. 


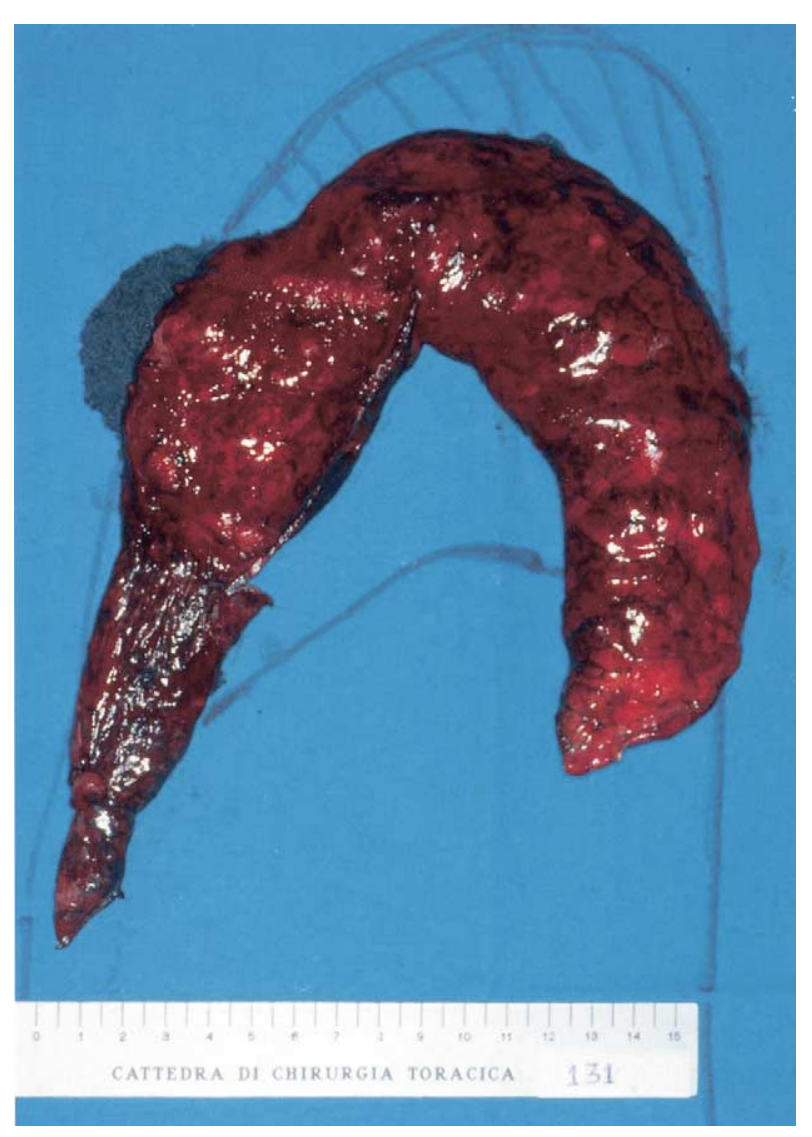

Figure 2. Completion lobectomy specimen (right upper lobe) after bilateral LVR.

tions. The mean in-hospital stay was 11 days. Meaningful improvements occurred in all survivors 6 months after CL, as detailed in Table 1. Right heart catheterization showed no significant changes in pulmonary artery pressure.

So far, no patient is dead or mechanically ventilated. Severe osteoporosis developed in 1 patient because of prolonged steroid therapy.

This is the first report dealing with redo LVR in patients with cigarette smoking-related severe emphysema and upper lobe predominance. Stammberger and coworkers ${ }^{3}$ have already reported on a patient with $\alpha_{1}$-antytripsin deficiency emphysema, who also benefited from redo LVR.

CL resulted in meaningful functional improvements in 3 of 4 patients, and in no instance did pulmonary hypertension, which can occur after bilateral LVR, ${ }^{4}$ develop. Nonetheless, 1 patient died of respiratory failure after surgery. We believe that he probably had too-advanced disease in the remaining lung tissue, with a scarcely heterogeneous pattern of emphysema.

Anatomic resection is considered contraindicated in patients with emphysema because of the risk of removal of functioning lung tissue. However, lobectomy has been recently reported ${ }^{5}$ as a successful LVR procedure in patients with severely emphysematous lung lobes. Despite the very limited cohort, our results suggest that in stringently selected patients with a completely destroyed and functionally useless residual upper lobe, CL can be followed by meaningful improvements in respiratory function measures and exercise capacity.

We advise that CL be strictly performed in patients who have already benefited meaningfully from the first reduction, because it is highly unlikely that a patient who did not benefit from LVR initially will improve after CL. We believe that one reliable way of monitoring the patient's condition is observing the $\mathrm{FEV}_{1}$ decay. In fact, $\mathrm{FEV}_{1}$ is a reliable measure of the severity of chronic obstructive pulmonary disease and is correlated with the clinical benefit of LVR. Our data suggest that $\mathrm{FEV}_{1}$ decay is maximal between 12 and 24 months and becomes less steep subsequently. However, the unavoidable and sometimes accelerated functional decline observed after LVR emphasizes that more efforts must be devoted to improve the current surgical techniques.

We conclude that in carefully selected patients, CL can prolong the benefits of LVR, a surgical option that continues to stimulate active investigation and to raise concerns and skepticism but that can undoubtedly offer some hope to properly selected patients with severe emphysema.

This study was performed within the Research Fellowship Program Tecnologie e Terapie Avanzate in Chirurgia awarded by the Tor Vergata University.

\section{References}

1. National Emphysema Treatment Trial Research Group. A randomized trial comparing lung-volume-reduction surgery with medical therapy for severe emphysema. N Engl J Med. 2003;248:2059-73.

2. Ciccone AM, Meyers BF, Guthrie TJ, Davis GE, Yusen RD, Lefrak SS, et al. Long-term outcome of bilateral lung volume reduction in 250 consecutive patients with emphysema. J Thorac Cardiovasc Surg. 2003; $125: 513-25$

3. Stammberger U, Thurnheer R, Schmid RA, Russi EW, Weder W. Redo lung volume reduction surgery in a patient with $\alpha_{1}$-antitrypsin deficiency. Ann Thorac Surg. 2000;69:632-3.

4. Weg IL, Rossoff L, McKeon K, Graver LM, Scharf SM. Development of pulmonary hypertension after lung volume reduction surgery. Am J Respir Crit Care Med. 1999;159:552-6.

5. Yusen RD, Lefrak SS, Gierada DS, Davis GE, Meyers BF, Patterson GA, et al. A prospective evaluation of lung volume reduction surgery in 200 consecutive patients. Chest. 2003;123:1026-37. 